\title{
REVIEW ON PROPHYLACTIC ANTIBIOTICS FOR DENTAL PATIENTS WITH PROSTHETIC JOINTS
}

W.L. Chai, C.K. Yong, W.C. Ngeow. Review on prophylactic antibiotics for dental patients with prosthetic joints. Annal Dent Univ Malaya 2003; 10: 22-26.

\section{ABSTRACT}

Most prosthetic joint infections originate from wound contamination or haematogenous seeding from distant sites of infection. Bacteraemia may follow dental treatment but there is little evidence of it related to prosthetic joint infection. Nevertheless, controversy continues with regards to the effect of dental treatment in patients with prosthetic joints. This article reviews current English literature regarding the use of antibiotic prophylaxis in the dental management of patients with prosthetic joints. Routine antibiotic prophylaxis is not recommended for every patient with prosthetic joints when receiving dental treatments. However, antibiotic prophylaxis may be prescribed for high-risk groups with predisposing factors to infection when undergoing dental treatment with high risk of bacteraemia.

Key words: dental treatment, prosthetic joint, bacteraemia.

\section{INTRODUCTION}

Replacement of diseased joints started in the 1950s. Initially post-operative infection rates of 15 to $25 \%$ were reported (1-5). With intra-operative antibiotic prophylaxis, modern operation theatre designs and surgical techniques, prosthetic joint infection rate has dropped to 0.5 to $5 \%$ (6). The consequences of prosthetic joint infection are devastating, entailing prolonged hospitalisation and antibiotics, multiple surgeries, significant morbidity and mortality (7). Early prosthetic joint infections happen within 2 months of operation, mostly from direct inoculation or airborne contamination, while late infection after 2 months of operation is usually the result of haematogenous seeding or contagious spread. Bacteraemia from surgical and dental treatments has been implicated in late haematogenous spread $(8,9)$. Understandable concern about the disastrous consequences of prosthetic joint infection has led to advocacy of prophylactic use of antibiotic before a dental procedure. However, it is important to recognise that routine use of prophylactic antibiotic has little supporting evidence, and is not without its own adverse effect.
Original Article

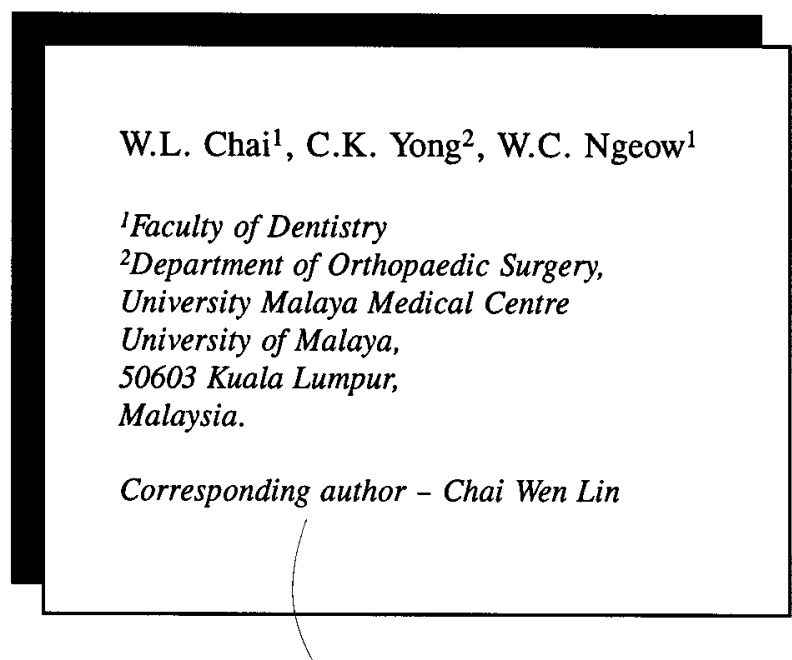

DENTAL TREATMENT BACTERAEMIAS

The role of dental treatment bacteraemia as the source of prosthetic joint infection has been disputed. It has been suggested that bacteraemias can cause haematogenous seeding of total joint implants, both in the early postoperative period and for many years following implantation (10). It appears that the most critical period is up to two years after joint replacement (11). However, it has been shown that bacteraemias may occur in the course of normal daily life $(12,13,14)$ and concurrently with dental and medical procedures (14). Guntheroth suggested that more oral bacteraemias are spontaneously induced by daily events than are dental treatment-induced (14).

The predominant pathogens in prosthetic joint infection are Staphylococcus aureus and Staphylococcus epidermidis, accounting for $54 \%(15)$. These microorganisms are more commonly found on the epidermis. In contrast, the commonest human oral flora like Streptococci viridans and Peptostreptococcus are only implicated in $0.07 \%$ of prosthetic joint infection (16).

Ching et al., found 4 cases of infected joints due to streptococci viridans but they were related to acute oral infection, and not dental treatment-induced bacteraemia(17). Out of twenty-one reported prosthetic joint infections after a dental procedure or infection, Thyne \& Ferguson found only one case close to meeting criteria of being related to dental treatmentinduced bacteraemia (8). Bartzokas et al., reported 4 cases of prosthetic joint infection caused by $S$. sanguis of the viridans group, with same strain isolated from the mouth and from the infected prosthesis. However all these four cases had history of caries and periodontal disease and the prosthetic joint infections were thought not associated to dental treatmentinduced bacteraemia (18). 
On the other hand, Waldman et al. reported nine infected total knee arthroplasties associated with dental procedures, five of which had predisposing systemic risk factors, and all the dental procedures were extensive in nature, lasting more than 75 minutes (9). LaPorte et al. reported of the 52 late infections identified among 2973 patients after total hip arthroplasty, three $(6 \%)$ were strongly associated with a dental procedure. Streptococcus viridans was identified in two cases and Peptostreptococcus in one. These were attributed to predisposing conditions, of which one patient had diabetes mellitus and another rheumatoid arthritis (16).

\section{COST EFFECTIVENESS OF ANTIBIOTIC PROPHYLAXIS PRIOR TO DENTAL TREATMENT}

Before recommending routine antibiotic prophylaxis for dental treatment in patients with joint replacements, the cost effectiveness and risk of these regimes should be evaluated.

In 1985, with calculated risk of infection from dental procedures at $0.03 \%$, Norden estimated that if 30 prosthetic joints infection were to occur in 100,000 total hip replacements, the overall cost of treatment without prophylaxis would be US $\$ 900,000$. The cost estimated of antibiotic prophylaxis would be US \$ $1,500,000$ with 40 cases of anaphylaxis resulting in 4 deaths. Norden's analysis did not show that prophylaxis was cost effective (19).

Jacobson et al. in 1991 performed a decision-utility analysis to compare the costs in one million hypothetical patients with prosthetic joints having dental treatment. Without antibiotic prophylaxis, the risk of late prosthetic joint infection after a dental visit was 29.3 per one million dental visits, resulting in 1.93 deaths, and 2.93 amputations at a total cost of US $\$ 2.29$ million. With routine prophylaxis using penicillin, there would be 400 cases of anaphylaxis, 2.31 deaths, and 2.14 amputations at a total cost of US \$6.4 million. However, prophylaxis with cephalexin would result in 200 anaphylaxis, 0.75 deaths, and 0.46 amputations at total cost of US $\$ 13.3$ million, with the cost per life saved at US $\$ 9.3$ million. This study suggested that the risk of deaths out-weighed the benefit in routine use of penicillin than without antibiotic prophylaxis. Though cephalexin is twice as expensive as penicillin, its use would significantly reduce the rate of both death and amputations compare with the use of penicillin or without antibiotic prophylaxis (20).

In order to maximise the cost effectiveness while minimising the potential toxicity, it has been suggested that antibiotic prophylaxis can be given only to highrisk patients, such as those who have had a previous joint replacement, complications related to joint replacements, systemic immunosuppressive disease, or a distant focus of acute infection $(8,20,21)$. If oneday oral cephalexin prophylaxis are given only to highrisk patients, it would result in 39 anaphylaxis, 0.38 deaths, 0.46 amputations at a total cost of US $\$ 5.2$ million. In addition, the cost effectiveness when cephalexin is routinely given would improve dramatically from US $\$ 9.3$ million per life saved to US \$1.9 million per life saved when only high-risk patients are given cephalexin (20).

\section{RECOMMENDATION OF AUTHORITY BODIES ON ANTIBIOTIC PROPHYLAXIS FOR DENTAL PATIENTS WITH TOTAL JOINT REPLACEMENT}

Despite most of the orthopaedic and dental surgeons supported antibiotic prophylaxis in patients with prosthetic joints undergoing dental treatments, and many more reviews against it $(22,23,24)$, there are currently only two main professional guidelines. One is the recommendation by the Working Party of the British Society for Antimicrobial Chemotherapy (BSAC) in 1992 (25), and the other a joint statement by the American Dental Association and the American Academy of Orthopaedic Surgeons (ADA/AAOS) in 1997 (26).

BSAC recommended against any use of antibiotic prophylaxis in dental patient with prosthetic joint replacement: "Advice of a Working Party of the British Society for Antimicrobial Chemotherapy is that patients with prosthetic joint implants (including total hip replacements) do not require antibiotic prophylaxis for dental treatment. The Working Party considers that it is unacceptable to expose patients to the adverse effects of antibiotics when there is no evidence that such prophylaxis is of any benefit, but that those who develop any intercurrent infection require prompt treatment with antibiotics to which the infecting organisms are sensitive". The Working Party had commented that joint infections have rarely been shown to follow dental procedures and were even more rarely caused by oral streptococci.

A slightly different stand was taken by the ADA/ AAOS: "Antibiotic prophylaxis is not indicated for dental patients with pins, plates and screws, nor is it routinely indicated for most dental patients with total joint replacements. However, it is advisable to consider premedication in a small number of patients (Table 1) who may be at potential increased risk of haematogenous total joint infection". The latest advisory statement issued by ADA/AAOS, which is the first periodic update of the 1997 statement and was recently published in the Journal of the American Dental Association (27), again echoed the same finding and recommendation. The 2003 statement includes some modifications of the classification of patients at potential risk and of the incidence stratification of bacteremic dental procedures. These changes have been 
Table 1. Patients who may be at potential increased risk of haematogenous total joint infection (27)

A. All patients during the first two (2) years after prosthetic joint replacement.

B. Immunocompromised / immunosuppressed patients:

- Inflammatory arthropathies: rheumatoid arthritis, systemic lupus erythematosus

- Drug-induced immunosuppression

- Radiation-induced immunosuppression

C. Patients with co-morbidities e.g.:

- Previous prosthetic joint infections

- Malnutrition

- Haemophilia

- HIV infection

- Insulin- dependent (Type 1) diabetes

- Malignancy

incorporated into tables 1 and 2. The following Table 2 summarises incidence stratification of bacteremic dental procedures (27).

\section{ANTIBIOTICS RECOMMENDED}

For patients not allergic to penicillin, the ADA/AAOS $(26,27)$ recommended a single-regime of 2 grams of cephalexin, cephradine or amoxicillin orally 1 hour prior to dental procedure. If the person is allergic to Penicillin, a dose $600 \mathrm{mg}$ of clindamycin can be given orally 1 hour prior to dental procedure.

For patients not allergic to penicillin but unable to take oral medication, cefazolin 1 gram or ampicillin 2 grams should be given IM/IV 1 hour prior to the procedure. Patients who are allergic to penicillin and unable to take oral medications need to be given clindamycin $600 \mathrm{mg}$ IM/IV 1 hour prior to the procedure.

In a recent review, Curry \& Phillips found no new evidence to change the ADA/AAOS recommendation, and agreed that all the above drugs can be safely given as a single-dose prophylaxis (28).

\section{ORAL HEALTH CARE STATUS}

For patients undergoing total joint replacement, the ADA/AAOS recommended that they should be in good dental health prior to surgery, and when necessary should be encouraged to seek professional dental care early. Patients who already have had a total joint arthroplasty should perform effective daily oral hygiene procedures to remove plaque (e.g. manual or powered toothbrushes, interdental cleaners, oral irrigators) to establish and maintain good oral health. The risk of bacteraemia is far more substantial in a
Table 2. Incidence stratification of bacteremic dental procedures (After ADA/AAOS)

HIGHER INCIDENCE (a)

- Dental extractions

- Periodontal procedures including surgery, subgingival placement of antibiotic fibres/strips, scaling and root planning, probing, recall maintenance

- Dental implant placement and reimplantation of avulsed teeth

- Endodontic (root canal) instrumentation or surgery only beyond the apex

- Initial placement of orthodontic bands but not brackets

- Intraligamentary and intraosseouslocal anaesthetic injections

- Prophylactic cleaning of teeth or implants where bleeding is anticipated

\section{LOWER INCIDENCE (b)(c)}

- Restorative dentistry (d) (operative and prosthodontic) with/without retraction cord

- Local anaesthetic injections (nonintraligamentary and nonintraosseous)

- Intracanal endodontic treatment; post-placement and buildup

- Placement of rubber dam

- Postoperative suture removal

- Placement of removable prosthodontic/orthodontic appliances

- Taking of oral impressions

- Fluoride treatments

- Taking of oral radiographs

- Orthodontic appliance adjustment

(a) Prophylaxis should be considered for patients with total joint replacement that meet the criteria in Table 1 . No other patients with orthopaedic implants should be considered for antibiotic prophylaxis prior to dental treatment/procedures.

(b) Prophylaxis not indicated.

(c) Clinical judgement may indicate antibiotic use in selected circumstances that may create significant bleeding.

(d) This includes restoration of carious (decayed) or missing teeth.

mouth with ongoing inflammation than in one that is healthy and employing these home-oral hygiene devices $(26,27)$.

Patients with total joint prosthesis and with acute orofacial infection should be vigorously treated as any other patient to eliminate the source of infection by incision and drainage, endodontics, extraction, and appropriate therapeutic antibiotics when indicated. Practitioners should always maintain a high index of suspicion for any unusual signs and symptoms, such as fever, swelling, pain, joint warm to touch, in patients with total joint prostheses $(17,25,29)$. 


\section{CONCLUSION}

According to current evidence, routine antibiotic prophylaxis is not recommended for all patients with prosthetic joints when receiving dental treatments. However, antibiotic prophylaxis may be prescribed for high-risk groups with predisposing factors to infection. However, the best measure in tackling late haematogenous spread prosthetic joint infection is by prevention. All patients planned for joint replacement should first visit their dental practitioners for treatment of dental disease, and subsequently practise regular dental check-up and proper oral hygiene lifelong.

\section{REFERENCES}

1. Hopkins CC. Recognition of endemic and epidemic prosthetic device infections: the role of surveillance, the hospital infection control practitioner, and the hospital epidemiologist. Infect Dis Clin North Am 1989; 3: 211-20.

2. Jaspers MT, Little JW. Prophylactic antibiotic coverage in patients with total arthroplasty: current practice. J Am Dent Assoc 1985; 111: 943-8.

3. Little JW. The need for antibiotic coverage for dental treatment of patients with joint replacements. Oral Surg Oral Med Oral Pathol 1983; 55: 20-3.

4. Segreti J, Levin S. The role of prophylactic antibiotics in the prevention of prosthetic device infections. Infect Dis Clin North Am 1989; 3: 357-70.

5. Sugarman B, Young EJ. Infections associated with prosthetic devices: magnitude of the problem. Infec Dis North Am 1989; 3: 187-98.

6. Bengtson $S$, Knutson $K$. The infected knee arthroplasty. A 6-year follow-up of 357 cases. Acta Orthop. Scand 1991; 62: 301-11.

7. Insall JN, Thompson FM, Brause BD. Two-stage reimplantation for the salvage of infected total knee arthroplasty. J Bone Joint Surg Am 1983; 65: 1087-98.

8. Thyne GM, Ferguson JW. Antibiotic prophylaxis during dental treatment in patients with prosthetic joints. J Bone Joint Surg Br 1991; 73: 191-4.

9. Waldman BJ, Mont MA, Hungerford DS. Total knee arthroplasty infections associated with dental procedures. Clin Orthop 1997; 343: 164-72.
10. Rubin R, Salvati EA, Lewis R. Infected total hip replacement after dental procedures. Oral Surg Oral Med Oral Pathol 1976; 41: 13-23.

11. Hansen AD, Osmon DR, Nelson CL. Prevention of deep periprosthetic joint infection. Instr Course Lect. 1997; 46: 555-67.

12. Bender IB, Naidorf IJ, Garvey GJ. Bacterial endocarditis: A consideration for physicians and dentists. J Am Dent Assoc 1984; 109: 415-20.

13. Everett ED, Hirschmann JV. Transient bacteremia and endocarditis prophylaxis: A review. Medicine (Baltimore) 1977; 56: 61-77.

14. Guntheroth WG. How important are dental procedures as a cause of infective endocarditis? Am J Cardiol 1984; 54: 797-801.

15. Maderazo EG, Judson S, Pasternak H. Late infections of total joint prostheses: a review and recommendations for prevention. Clin Orthop 1988; 229: 131-42.

16. Laporte DM, Waldman BJ, Mont MA, Hungerford DS. Infections associated with dental procedures in total hip arthroplasty. J Bone Joint Surg $\mathrm{Br}$ 1999; 81: 56-9.

17. Ching DW, Gould IM, Rennie JA, Gibson PH. Prevention of late haematogenous infection in major prosthetic joints. J Antimicrob Chemother 1989; 23: 676-80.

18. Bartzokas CA, Johnson R, Jane M, Martin MV, Pearce PK, Saw Y. Relation between mouth and haematogenous infection in total joint replacements. BMJ 1994; 309: 506-8.

19. Norden CW. Prevention of bone and joint infections. Am J Med 1985; 78: 229-32.

20. Jacobson JJ, Schweitzer SO, Kowalski CJ. Chemoprophylaxis of prosthetic joint patients during dental treatment: a decision-utility analysis. Oral Surg Oral Med Oral Pathol 1991; 72: 16777.

21. Deacon JM, Pagliaro AJ, Zelicof SB, Horowitz HW. Current concepts review: prophylaxis use of antibiotics for procedures after total joint replacement. J Bone Joint Surg Am 1996; 78: 1755-70.

22. Little JW. Patients with prosthetic joints: are they at risk when receiving invasive dental procedures? Spec Care Dentist 1997; 17: 153-60. 
23. Council on Dental Therapeutics. Management of dental patients with prosthetic joints. J Am Dent Assoc 1990; 121: 537-8.

24. Tong DC, Rothwell BR. Antibiotic prophylaxis in dentistry: A review and practice recommendations. J Am Dent Assoc 2000; 131: 366-74.

25. Simmons NA, Ball AP, Cawson RA, Eykyn SJ, Hughes SP, McGowan DA, Shanson DC. Case against antibiotic prophylaxis for dental treatment of patients with joint prostheses. Lancet 1992; 39: 301.

26. American Dental Association and American Academy of Orthopedic Surgeons. Advisory statement: Antibiotic prophylaxis for dental patients with total joint replacements. Journal of the American Dental Association 1997; 128: 10048.
27. American Dental Association and American Academy of Orthopedic Surgeons. Advisory statement: Antibiotic prophylaxis for dental patients with total joint replacements. J Am Dent Assoc. 2003; 134: 895-9.

28. Curry S, Phillips H. Joint arthroplasty, dental treatment, and antibiotics: a review: J Arthroplasty 2002; 17: 111-3.

29. Pallasch TJ, Slots J. Antibiotic prophylaxis and the medically compromised patient. Periodontology 2000 1996; 10: 107-38. 